\title{
ACUTE AND SUBCHRONIC TOXICITY OF CHANTALEELA RECIPE IN RATS
}

\section{Seewaboon Sireeratawong, ${ }^{1}$ Nattakarn Chiruntanat, ${ }^{2}$ Urarat Nanna, ${ }^{1}$ Nirush Lertprasertsuke, ${ }^{3}$ Supachai Srithiwong, ${ }^{4}$ Noppamas Soonthornchareonnon, ${ }^{5}$ Kanjana Jaijoy, ${ }^{6}$}

${ }^{1}$ Division of Pharmacology, Department of Preclinical Science, Faculty of Medicine, Thammasat University, Pathum Thani 12120, Thailand. ${ }^{2}$ Department of Pharmacology, Faculty of Medicine, Chiang Mai University, Chiang Mai 50200, Thailand. ${ }^{3}$ Department of Pathology, Faculty of Medicine, Chiang Mai University, Muang, Chiang Mai 50200, Thailand. ${ }^{4}$ Department of Animal Science, Faculty of Agricultural Technology, Chiang Mai Rajabhat University, Chiang Mai, 50300 Thailand. ${ }^{5}$ Department of Pharmacognosy, Faculty of Pharmacy, Mahidol University, Bangkok 10400, Thailand. ${ }^{6}$ Research Unit of Pharmacology and Toxicology of Natural Products, Faculty of Medicine, Thammasat University, Pathum Thani 12120, Thailand.

*E-mail: seewaboon@gmail.com

\begin{abstract}
Acute and subchronic toxicities of Chantaleela recipe were studied in both male and female rats. Oral administration of the extract at a single dose of $5,000 \mathrm{mg} / \mathrm{kg}$ body weight ( 5 females, 5 males) did not produce signs of toxicity, behavioral changes, mortality or differences on gross appearance of internal organs. The subchronic toxicity was determined by oral feeding the test substance at the doses of $600,1,200$ and 2,400 mg/kg body weight for 90 days (10 females, 10 males). No signs of abnormalities were observed in the test groups as compared to the controls. The test and control groups (on the $90^{\text {th }}$ day) and the satellite group (on the $118^{\text {th }}$ day) were analyzed by measuring their final body and organ weights, taking necropsy, and examining hematological parameters, blood clinical chemistry and histopathology features. The results suggest that Chantaleela recipe did not cause acute or subchronic oral toxicities to female and male rats.
\end{abstract}

Key words: Acute toxicity, Subchronic toxicity, Chantaleela recipe

\section{Introduction}

Chantaleela recipe has long been prescribed in Thai traditional folk medicine. It is composed of eight kinds of herbal plants including Atractylodes lancea, Angelica sylvestris, Artemisia vulgaris, Dracaena loureiri, Eurycoma longifolia, Gymnopetalum cochinchinense, Myristica fragrans, and Tinospora crispa. According to Thai folk medicine, this recipe prepared in powder or tablet form has been widely used for relieving common fever (National Drug Committee, Ministry of Public Health, 2006). The toxicological evaluation of this medicinal remedy demonstrated a high safety profile (Ngamwat et al., 1987). The $50 \%$ lethal dose $\left(\mathrm{LD}_{50}\right)$ of the alcoholic extract of Chantaleela was $13.22 \mathrm{~g} / \mathrm{kg}$ in Swiss mice (intraperitoneally injection). The albino rats received the diet supplemented with the ten percent of the alcoholic extract of Chantaleela (at a high dose of $40 \mathrm{mg} / \mathrm{kg}$ ), which was 80 times higher than the normal dose used in humans. There was no abnormal finding in organ function and clinical laboratory value. However, the acute and long term oral toxicity of Chantaleela recipe has not been evaluated. Thus, the aim of the present study was to investigate the adverse effects related to different doses of the standardized alcoholic extract in order to find the acceptably safe level by determining both oral acute and subchronic toxicities in rats.

\section{Materials and methods \\ Plant materials and preparation of Chantaleela recipe}

All plant materials were kindly provided by Thai traditional medicine doctor. The preparation of the crude extract of Chantaleela recipe was developed in our laboratory by a consecutive extraction with three solvents including hexane, 95\% ethanol and water, and then spray dried. The quality control of raw materials and extracts was followed by Thai Herbal Pharmacopoeia (organoleptic examination, \% loss on drying, extractive values, total ash and acid insoluble ash). The percent amount of volatile oil, type of chemical constituents in oils (detected by GC/MS), chemical constituents (flavonoids, lactone, terpnoids and tannins) in raw materials and extracts, and TLC fingerprints were also determined.

Experimental animals

Male and female Sprague-Dawley (SD) rats, weighing 180-200 g were obtained from the National Laboratory Animal Center, Nakorn Pathom, Thailand. They were housed under standard environmental conditions of temperature at $24 \pm$ $1^{\circ} \mathrm{C}$ under a $12 \mathrm{~h}$ dark-light cycle, and allowed free access to drinking water and standard pellet diet. Rats were deprived of food except water 16-18 hour prior the experiments. All experimental protocols were approved by the Animal Ethics Committee of Faculty of Medicine, Thammasat University (No. 0002/2007). 


\section{Acute oral toxicity in rats (OECD, 2001; WHO, 2000)}

Ten rats were randomly divided into two groups of five animals per sex. Chantaleela extract at a single dose of $5,000 \mathrm{mg} / \mathrm{kg}$ body weight was given orally to the rats, while the control group received water vehicle. Body weight, signs of toxicity and mortality were observed after the administration at the first, second, fourth and sixth hour and once daily for 14 days. On the $15^{\text {th }}$ day, all rats were sacrificed and internal organs were observed macroscopically. All internal organs were placed in $10 \%$ neutral buffered formadehyde solution and performed by histopathological examination.

\section{Subchronic oral toxicity in rats (WHO, 2000; OECD, 1981)}

Chantaleela recipe at the doses of $600,1,200$ and 2,400 mg/kg were given orally to each group of rats daily for 90 days, while the control group received water vehicle. In order to assess reversibility effect, the extract at the dose of 2,400 $\mathrm{mg} / \mathrm{kg}$ was given once daily to the fifth group of rats for 90 days, and kept for another 28 days post treatment. Toxic manifestations such as signs of toxicity, mortality and the body weight changes were monitored daily. On day $91^{\text {st }}$ and $118^{\text {th }}$ (satellite groups), rats were anesthetized with thiopental sodium. Heparinized blood samples were taken for hematological examination. The serum from non-heparinized blood was carefully collected for blood chemistry and enzyme analysis. All rats were sacrificed after the blood collection. The internal organs and some tissues were weighed to determine relative organs weights and observed for gross lesions. All tissues were preserved in $10 \%$ neutral buffered formadehyde solution for histopathological examination.

\section{Statistical analysis}

Results were expressed as mean \pm standard error of mean (S.E.M.). Statistical significance was determined by oneway analysis of variance (ANOVA) and post hoc least-significant difference test. The data obtained from acute toxicity studies were analyzed using Student's paired $t$-test. $P$ values less than 0.05 were considered significant.

\section{Results \\ Acute oral toxicity}

Chantaleela recipe at a single dose of $5,000 \mathrm{mg} / \mathrm{kg}$ caused neither sign of toxicity nor death of rats during 14 days of the experimental period. There were no significant changes in body weight, food consumption and internal organ weight of either sex between the treated rats and the control rats (data not shown). Moreover, the gross and histopathological examinations of the internal organs revealed no pathological abnormality as compared with the control.

\section{Subchronic oral toxicity}

The subchronic oral administration of Chantaleela recipe $(600,1,200$ and 2,400 $\mathrm{mg} / \mathrm{kg})$ did not produce change in behaviour, toxic signs or mortality during the experimental period. The body weight and the weight gain in all of the treatment groups were significantly lower than those of the control groups (Table 1 ). On day $90^{\text {th }}$, both parameters were significantly decreased in the female treated $(600$ and $2,400 \mathrm{mg} / \mathrm{kg})$ and the male treated $(600 \mathrm{mg} / \mathrm{kg})$ groups as compared to that of the control group. During the experimental periods, the food intake of all groups was not significantly altered (data not shown).

As shown in Table 2, the female treated rats $(600$ and $2,400 \mathrm{mg} / \mathrm{kg}$ ) showed a significant increase in the liver weight. At the dose of $1,200 \mathrm{mg} / \mathrm{kg} / \mathrm{day}$, a significant weight increase of the uterus was found. The satellite female group showed significant decrease in spleen weight. In the male treated rats, the kidney weight significantly increased in the groups with the dose of 1,200 and $2,400 \mathrm{mg} / \mathrm{kg} /$ day whereas the spleen weight decreased with the highest dose of the extract. Besides, the satellite male group showed significant increases in the kidney, testis and epididymis weights. Next, necropsy and histopathology examinations were determined whether or not the organs or tissue had been damaged. The general appearances and the internal organs of rats receiving the extract showed normal structure, size, weight, shape, color, and texture. The results showed no macroscopic or microscopic changes in the internal organs of any of the treated rats.

Some of the hematological and differential white blood cell count values of treated rats were significantly different from those of the control group. The hematological parameters of female and male rats are listed in Tables 3 . In the female treated groups with $1,200 \mathrm{mg} / \mathrm{kg} /$ day, hematocrit (Hct) was significantly lower than the control. In the satellite female group, mean corpuscular volume (MCV) and mean corpuscular hemoglobin (MCH) were significantly higher than the control values. In the satellite male group, a slight but significant increase in the concentration of hemoglobin (Hb) was observed. However, the alteration of these numbers was minor and remained within the normal ranges. Table 4 shows the differential white blood cell count values of female and male treated groups. A significant increase in white blood cell (WBC) was observed in the female treated with 600 and 2,400 mg/kg/day. Moreover, a significant increase of neutrophil (Neu) but a decrease of eosinophil (Eo) were found in the female and male treated group with 2,400 mg/kg/day, respectively.

To test whether the substance impairs liver and kidney functions, clinical blood chemistry examination was performed in the female and male rats and the results are summarized in Table 5 and 6, respectively. The data indicates a significant decrease in creatinine in the female rats treated with the extract at the doses of $1,200 \mathrm{mg} / \mathrm{kg} / \mathrm{day}$. The concentrations of alkaline phosphatase (ALP) of female rats treated with 2,400 mg/kg/day were significantly increased as compared with those of the controls. In the satellite female group, only total protein and SGOT were significantly less than their control values. Furthermore, total protein and albumin significantly increased in the male treated with $1,200 \mathrm{mg} / \mathrm{kg} / \mathrm{day}$, and ALP increased in the group treated with $2,400 \mathrm{mg} / \mathrm{kg} / \mathrm{day}$ as compared with those of the controls. In the satellite male 
group, total bilirubin was significantly higher than the control. In this study, significant decreases and increases in clinical blood chemical values were observed in both female and male rats as compared to the control groups.

Table 1: Body weights of rats in the subchronic toxicity of Chantaleela recipe

\begin{tabular}{|c|c|c|c|c|}
\hline & \multicolumn{4}{|c|}{ Body weight (g) } \\
\hline & Day 0 & Day 90 & Day 118 & Weight gain on day 90 \\
\hline \multicolumn{5}{|l|}{ Female } \\
\hline Control & $180.60 \pm 5.70$ & $279.00 \pm 5.31$ & - & $98.40 \pm 2.84$ \\
\hline \multicolumn{5}{|l|}{ Chantaleela } \\
\hline 600 mg/kg & $179.80 \pm 3.23$ & $262.50 \pm 3.82 *$ & - & $82.70 \pm 3.71^{*}$ \\
\hline 1,200 mg/kg & $180.20 \pm 4.57$ & $270.50 \pm 3.53$ & - & $90.30 \pm 4.17$ \\
\hline $2,400 \mathrm{mg} / \mathrm{kg}^{\mathrm{a}}$ & $180.40 \pm 5.41$ & $262.50 \pm 4.42 *$ & - & $82.10 \pm 5.42 *$ \\
\hline $2,400 \mathrm{mg} / \mathrm{kg}^{\mathrm{b}}$ & $179.60 \pm 4.48$ & $270.50 \pm 3.83$ & $281.00 \pm 3.32$ & $90.90 \pm 3.84$ \\
\hline \multicolumn{5}{|l|}{ Male } \\
\hline Control & $192.60 \pm 4.09$ & $433.50 \pm 7.53$ & - & $240.90 \pm 5.59$ \\
\hline \multicolumn{5}{|l|}{ Chantaleela } \\
\hline $600 \mathrm{mg} / \mathrm{kg}$ & $193.00 \pm 8.27$ & $396.50 \pm 9.25^{*}$ & - & $203.50 \pm 8.28 *$ \\
\hline 1,200 mg/kg & $193.40 \pm 6.65$ & $420.00 \pm 7.85$ & - & $226.60 \pm 8.47$ \\
\hline $2,400 \mathrm{mg} / \mathrm{kg}^{\mathrm{a}}$ & $194.80 \pm 4.98$ & $415.50 \pm 9.98$ & - & $220.70 \pm 11.52$ \\
\hline $2,400 \mathrm{mg} / \mathrm{kg}^{\mathrm{b}}$ & $192.60 \pm 5.22$ & $445.00 \pm 7.85$ & $463.00 \pm 6.06$ & $252.40 \pm 6.19$ \\
\hline
\end{tabular}

All values are mean \pm S.E.M. $(\mathrm{n}=10)$; ${ }^{\mathrm{a}}$ A group was treated with Chantaleela recipe at $2,400 \mathrm{mg} / \mathrm{kg} / \mathrm{day}$ for 90 days.

${ }^{\mathrm{b}}$ A satellite group was treated with Chantaleela recipe at 2,400 mg/kg/day for 90 days followed by no treatment for 28 days.;

* Significantly different from control, $p<0.05$.

Table 2: Organ weights of rats in the subchronic toxicity of Chantaleela recipe

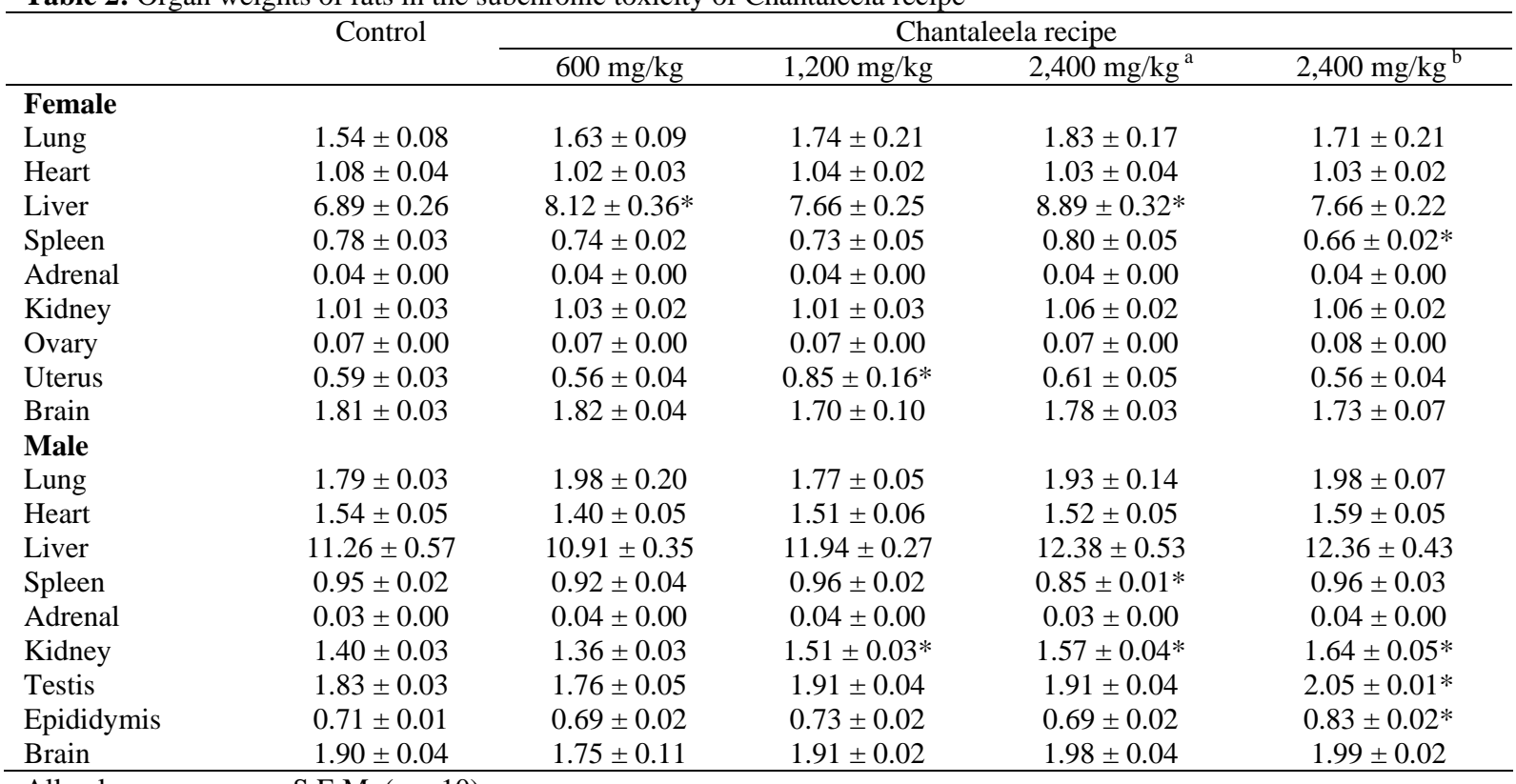

All values are mean \pm S.E.M. $(\mathrm{n}=10)$

${ }^{a}$ A group was treated with Chantaleela recipe at 2,400 mg/kg/day for 90 days.

${ }^{\mathrm{b}}$ A satellite group was treated with Chantaleela recipe at $2,400 \mathrm{mg} / \mathrm{kg} /$ day for 90 days followed by no treatment for 28 days.

* Significantly different from control, $p<0.05$.

Table 3: Hematological values of rats in the subchronic toxicity of Chantaleela recipe

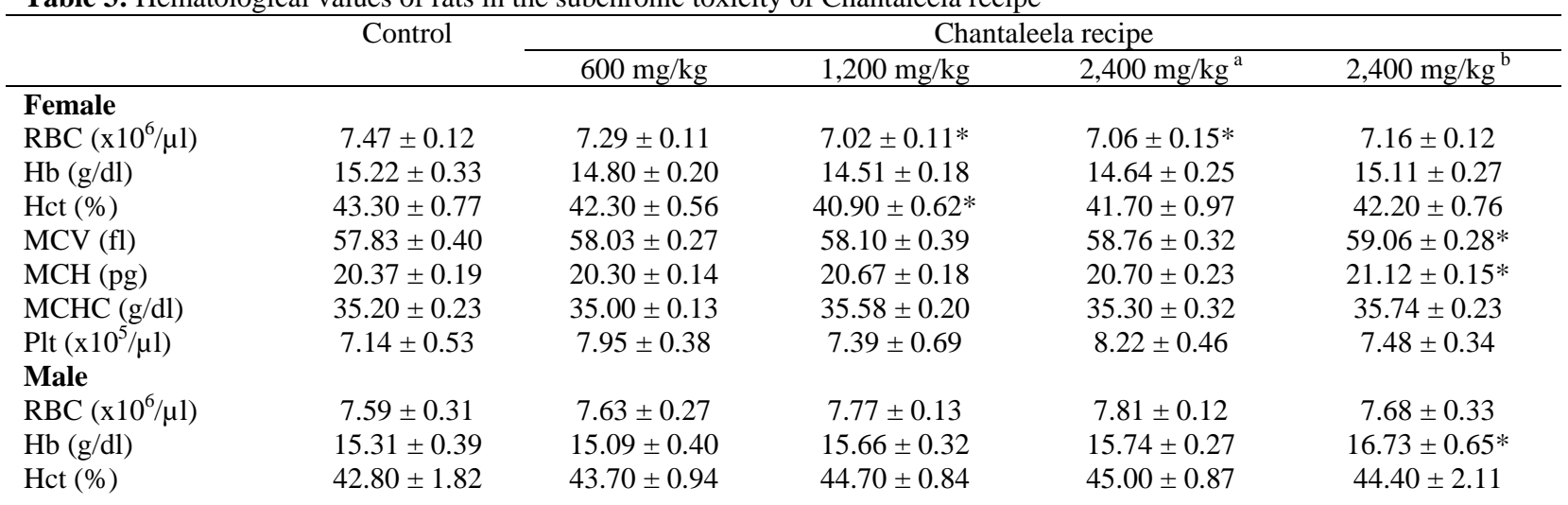




\begin{tabular}{lccccc} 
MCV (fl) & $56.32 \pm 0.25$ & $57.65 \pm 1.47$ & $57.31 \pm 0.25$ & $57.46 \pm 0.43$ & $57.66 \pm 0.64$ \\
MCH (pg) & $20.34 \pm 0.52$ & $19.87 \pm 0.32$ & $20.16 \pm 0.27$ & $20.16 \pm 0.15$ & $22.42 \pm 1.79$ \\
MCHC (g/dl) & $36.14 \pm 0.95$ & $34.52 \pm 0.35$ & $35.18 \pm 0.51$ & $35.10 \pm 0.26$ \\
Plt $(\mathrm{x} 10 / \mu \mathrm{l})$ & $8.08 \pm 0.38$ & $7.97 \pm 0.45$ & $7.40 \pm 0.58$ & $8.52 \pm 0.54$ & $8.02 \pm 0.15$ \\
\hline
\end{tabular}

All values are mean \pm S.E.M. $(n=10)$

${ }^{a}$ A group was treated with Chantaleela recipe at $2,400 \mathrm{mg} / \mathrm{kg} / \mathrm{day}$ for 90 days.

${ }^{\mathrm{b}}$ A satellite group was treated with Chantaleela recipe at 2,400 mg/kg/day for 90 days followed by no treatment for 28 days.

* Significantly different from control, $p<0.05$.

Table 4: Differential white blood cell count values of rats in the subchronic toxicity Chantaleela recipe

\begin{tabular}{|c|c|c|c|c|c|}
\hline & \multirow[t]{2}{*}{ Control } & \multicolumn{4}{|c|}{ Chantaleela recipe } \\
\hline & & $600 \mathrm{mg} / \mathrm{kg}$ & $1,200 \mathrm{mg} / \mathrm{kg}$ & $2,400 \mathrm{mg} / \mathrm{kg}^{\mathrm{a}}$ & $2,400 \mathrm{mg} / \mathrm{kg}^{\mathrm{b}}$ \\
\hline \multicolumn{6}{|l|}{ Female } \\
\hline $\mathrm{WBC}\left(\mathrm{x} 10^{3} / \mu \mathrm{l}\right)$ & $2.93 \pm 0.18$ & $4.43 \pm 0.53^{*}$ & $3.64 \pm 0.43$ & $4.61 \pm 0.48 *$ & $2.51 \pm 0.24$ \\
\hline Neu (\%) & $15.30 \pm 1.59$ & $16.70 \pm 1.84$ & $17.20 \pm 1.98$ & $24.20 \pm 4.00^{*}$ & $15.50 \pm 1.26$ \\
\hline Lymp (\%) & $74.10 \pm 1.88$ & $72.70 \pm 2.77$ & $73.90 \pm 2.29$ & $70.00 \pm 3.38$ & $73.10 \pm 1.43$ \\
\hline Mono (\%) & $7.80 \pm 0.49$ & $8.40 \pm 0.86$ & $7.00 \pm 0.74$ & $7.60 \pm 0.90$ & $8.60 \pm 0.54$ \\
\hline Eo (\%) & $2.00 \pm 0.39$ & $2.20 \pm 0.51$ & $1.90 \pm 0.55$ & $1.60 \pm 0.37$ & $2.80 \pm 0.59$ \\
\hline Baso (\%) & $0.00 \pm 0.00$ & $0.00 \pm 0.00$ & $0.00 \pm 0.00$ & $0.00 \pm 0.00$ & $0.00 \pm 0.00$ \\
\hline \multicolumn{6}{|l|}{ Male } \\
\hline WBC $\left(\mathrm{x} 10^{3} / \mu \mathrm{l}\right)$ & $4.76 \pm 0.54$ & $5.12 \pm 0.42$ & $4.94 \pm 0.49$ & $5.81 \pm 0.84$ & $4.17 \pm 0.40$ \\
\hline Neu (\%) & $17.60 \pm 2.02$ & $17.50 \pm 1.78$ & $22.90 \pm 4.18$ & $18.50 \pm 1.75$ & $13.60 \pm 1.18$ \\
\hline Lymp (\%) & $72.60 \pm 1.86$ & $72.50 \pm 2.15$ & $66.60 \pm 3.77$ & $71.10 \pm 1.86$ & $78.00 \pm 1.47$ \\
\hline Mono (\%) & $8.40 \pm 0.27$ & $9.20 \pm 0.76$ & $9.90 \pm 0.97$ & $10.00 \pm 0.54$ & $7.00 \pm 0.54$ \\
\hline Eo (\%) & $1.40 \pm 0.40$ & $0.80 \pm 0.33$ & $0.60 \pm 0.27$ & $0.40 \pm 0.16^{*}$ & $1.40 \pm 0.27$ \\
\hline Baso (\%) & $0.00 \pm 0.00$ & $0.00 \pm 0.00$ & $0.00 \pm 0.00$ & $0.00 \pm 0.00$ & $0.00 \pm 0.00$ \\
\hline
\end{tabular}

All values are mean \pm S.E.M. $(n=10)$

${ }^{a}$ A group was treated with Chantaleela recipe at 2,400 mg/kg/day for 90 days.

${ }^{\mathrm{b}}$ A satellite group was treated with Chantaleela recipe at 2,400 mg/kg/day for 90 days followed by no treatment for 28 days.

* Significantly different from control, $p<0.05$.

\section{Discussion}

Chantaleela recipe has long been given in Thai traditional folk medicine for relieving fever. The present study demonstrated the safety profile of Chantaleela recipe in acute and subchronic oral toxicity in SD rats. The acute oral administration of a single high dose did not produce the toxic signs or change in behaviour. These results suggest that Chantaleela recipe is virtually not toxic after an acute exposure. Based on these, the $\mathrm{LD}_{50}$ value of Chantaleela recipe was greater than $5,000 \mathrm{mg} / \mathrm{kg}$ for both sexes.

Table 5: Clinical blood chemistry values of female rats in the subchronic toxicity of Chanataleela recipe

\begin{tabular}{lccccc}
\hline & Control & \multicolumn{4}{c}{ Chantaleela recipe } \\
\cline { 2 - 5 } & & $600 \mathrm{mg} / \mathrm{kg}$ & $1,200 \mathrm{mg} / \mathrm{kg}$ & $2,400 \mathrm{mg} / \mathrm{kg}^{\mathrm{a}}$ & $2,400 \mathrm{mg} / \mathrm{kg}^{\mathrm{b}}$ \\
\hline Glucose (mg/dl) & $128.60 \pm 6.94$ & $130.30 \pm 7.61$ & $126.10 \pm 5.83$ & $122.20 \pm 8.30$ & $145.80 \pm 8.12$ \\
BUN (mg/dl) & $23.00 \pm 1.26$ & $22.40 \pm 0.94$ & $20.50 \pm 0.64$ & $22.40 \pm 1.01$ & $25.00 \pm 0.80$ \\
Creatinine (mg/dl) & $0.44 \pm 0.03$ & $0.42 \pm 0.01$ & $0.34 \pm 0.02^{*}$ & $0.40 \pm 0.00$ & $0.41 \pm 0.02$ \\
Total protein (g/dl) & $6.04 \pm 0.16$ & $6.21 \pm 0.13$ & $5.92 \pm 0.18$ & $6.36 \pm 0.15$ & $5.57 \pm 0.15^{*}$ \\
Albumin (g/dl) & $3.95 \pm 0.07$ & $3.96 \pm 0.15$ & $3.73 \pm 0.07$ & $3.86 \pm 0.07$ & $3.66 \pm 0.16$ \\
Total bilirubin & $0.23 \pm 0.01$ & $0.23 \pm 0.01$ & $0.22 \pm 0.01$ & $0.26 \pm 0.02$ & $0.28 \pm 0.03$ \\
(mg/dl) & & & & \\
Direct bilirubin & $0.00 \pm 0.00$ & $0.01 \pm 0.01$ & $0.00 \pm 0.00$ & $0.00 \pm 0.00$ & $0.01 \pm 0.01$ \\
(mg/dl) & & & & \\
SGOT (U/l) & $183.20 \pm 44.32$ & $142.70 \pm 17.95$ & $136.70 \pm 24.75$ & $155.00 \pm 21.76$ & $101.30 \pm 8.11^{*}$ \\
SGPT (U/l) & $57.40 \pm 18.48$ & $48.20 \pm 5.53$ & $38.80 \pm 5.06$ & $44.50 \pm 6.58$ & $33.10 \pm 2.00$ \\
ALP (U/l) & $51.10 \pm 6.28$ & $48.70 \pm 2.54$ & $64.30 \pm 10.20$ & $73.90 \pm 12.27^{*}$ & $41.30 \pm 1.85$ \\
\hline All & & & & \\
\hline
\end{tabular}

All values are mean \pm S.E.M. $(n=10)$

${ }^{\text {a }}$ A group was treated with Chantaleela recipe at 2,400 mg/kg/day for 90 days.

${ }^{\mathrm{b}}$ A satellite group was treated with Chantaleela recipe at 2,400 mg/kg/day for 90 days followed by no treatment for 28 days.

* Significantly different from control, $p<0.05$. 
Table 6: Clinical blood chemistry values of male rats in the subchronic toxicity of Chantaleela recipe

\begin{tabular}{lccccc}
\hline & Control & \multicolumn{4}{c}{ Chantaleela recipe } \\
\cline { 2 - 5 } & & $600 \mathrm{mg} / \mathrm{kg}$ & $1,200 \mathrm{mg} / \mathrm{kg}$ & $2,400 \mathrm{mg} / \mathrm{kg}^{\mathrm{a}}$ & $2,400 \mathrm{mg} / \mathrm{kg}^{\mathrm{b}}$ \\
\hline Glucose (mg/dl) & $132.20 \pm 3.39$ & $136.80 \pm 4.12$ & $137.20 \pm 5.99$ & $142.50 \pm 8.32$ & $127.70 \pm 4.11$ \\
BUN (mg/dl) & $23.90 \pm 0.60$ & $24.20 \pm 0.71$ & $22.50 \pm 0.88$ & $22.70 \pm 0.88$ & $22.50 \pm 0.64$ \\
Creatinine (mg/dl) & $0.35 \pm 0.02$ & $0.34 \pm 0.02$ & $0.35 \pm 0.02$ & $0.33 \pm 0.02$ & $0.35 \pm 0.02$ \\
Total protein (g/dl) & $5.75 \pm 0.08$ & $5.71 \pm 0.04$ & $6.05 \pm 0.15^{*}$ & $5.95 \pm 0.07$ & $5.64 \pm 0.13$ \\
Albumin (g/dl) & $3.49 \pm 0.06$ & $3.47 \pm 0.03$ & $3.74 \pm 0.08^{*}$ & $3.62 \pm 0.07$ & $3.52 \pm 0.07$ \\
Total bilirubin & $0.22 \pm 0.02$ & $0.18 \pm 0.01$ & $0.20 \pm 0.00$ & $0.20 \pm 0.00$ & $0.28 \pm 0.02^{*}$ \\
(mg/dl) & & & & \\
Direct bilirubin & $0.00 \pm 0.00$ & $0.00 \pm 0.00$ & $0.00 \pm 0.00$ & $0.00 \pm 0.00$ & $0.00 \pm 0.00$ \\
(mg/dl) & & & & \\
SGOT (U/l) & $114.10 \pm 8.04$ & $104.30 \pm 3.77$ & $108.30 \pm 6.11$ & $118.70 \pm 14.56$ & $111.20 \pm 7.94$ \\
SGPT (U/l) & $39.70 \pm 2.05$ & $36.60 \pm 1.31$ & $43.20 \pm 3.85$ & $40.40 \pm 2.69$ & $47.70 \pm 5.45$ \\
ALP (U/l) & $59.70 \pm 1.84$ & $61.00 \pm 1.69$ & $70.60 \pm 3.50$ & $72.90 \pm 7.01^{*}$ & $57.30 \pm 2.41$ \\
\hline All & & & & \\
\hline
\end{tabular}

All values are mean \pm S.E.M. $(\mathrm{n}=10)$

${ }^{a}$ A group was treated with Chantaleela recipe at 2,400 mg/kg/day for 90 days.

${ }^{\mathrm{b}}$ A satellite group was treated with Chantaleela recipe at 2,400 mg/kg/day for 90 days followed by no treatment for 28 days.

* Significantly different from control, $p<0.05$.

Although the body weight and the weight gain in the extract-treated groups were significantly different from those of the control animals, such changes may not be of clinical significance because the differences were very small and within normal limit. Some internal organ weights were significantly changed in treated rats of both sexes. Nonetheless, all of the decrease was minor and the differences may have been due to the variation in size of internal organs and/or body weight of the animals (Bailey et al., 2004; Levine, 2002). These observations were further validated by histopathological examination. No significant histopathological change was found in any organ of the extract-treated animals suggesting the extract does not affect the organ function.

The hematologic system is very sensitive to toxic compounds and can be altered by the ingestion of some toxic plants. The parameters usually measured are hemoglobin, packed cell volume, white blood cell count, platelet count (Adeneye et al., 2006). Moreover, analysis of white blood cell count (basophil, eosinophil, lymphocyte, monocyte, and neutrophil) is frequently required in order to evaluate immune system (Williams et al., 1990). Nevertheless, all values lied within the normal limits; the results can be considered as normal for this animal species (Inala et al., 2002). Therefore, these results suggest that Chantaleela recipe did not cause hematological or immunological defects.

Clinical blood chemistry examination was performed in order to evaluate any toxic effects on the pancreas function (glucose), kidney function (BUN, creatinine) and liver function (SGOT, SGPT, ALP, total protein, albumin, total and direct bilirubin). The alteration of these values was however small and remained within the normal range (Angkhasirisap et al., 2002; Sacher and McPherson, 2000; Caisey and King, 1980). So, the extract of Chantaleela recipe did not induce toxicity to the kidney and liver.

In summary, Chantaleela recipe administered orally did not cause acute or subchronic toxicities in both female and male rats. A chronic toxicity study of the doses consumed in tradition medicine should be further carried out to assess the long-term safety of the extract.

\section{Acknowledgements}

The authors are thankful to the National Research Council of Thailand for the financially supported.

\section{References}

1. Adeneye, A.A., Ajagbonna, O.P., Adeleke, T.I. and Bello, S.O. (2006). Preliminary toxicity and phytochemical studies of the stem bark aqueous extract of Musanga cecropioides in rats. J. Ethnopharmacol. 105(3): 374 - 379.

2. $\quad$ Angkhasirisap, W., Inala, P., Sirimontaporn, A., Inpunkaew, R., Rungrojejinda, K., Kengkoom, K., Ratanasak, W. and Buripadi Lawson, D. (2002). Blood chemistry profiles of outbred Sprague-Dawley rat in The Facility of National Laboratory Animal Centre. $28^{\text {th }}$ Congress on Science and Technology of Thailand.

3. Bailey, S.A., Zidell, R.H. and Perry, R.W. (2004). Relationships between organ weight and body/brain weight in the rat: what is the best analytical endpoint? Toxicol. Pathol. 32(4): $448-466$.

4. Caisey, J.D. and King, D.J. (1980). Clinical chemical values for some common laboratory animals. Clin. Chem. 26: $1877-1879$.

5. Inala, P., Sirimontaporn, A., Inpunkaew, R., Rungrojejinda, K., Kengkoom, K., Ratanasak, W. and Buripakdi Lawson, D. (2002). Hematological analysis of outbred Sprague-Dawley rat in The Facility of National Laboratory Animal Centre. $28^{\text {th }}$ Congress on Science and Technology of Thailand.

6. Levine, B.S. (2002). Animal Clinical Pathology. In: Derelanko, M.J., Hollinger, M.A. (eds) CRC Handbook of Toxicology, $2^{\text {nd }}$ ed. CRC Press, USA, pp $742-768$. 
7. National Drug Committee, Ministry of Public Health. (2006). National List of Essential Medicines of Thailand 2006. The Agricultural Co-operative Federation of Thailand Limited, Bangkok.

8. Ngamwat, W., Chawalidthumrong, P., Permpipat, U., Leelakulthanit, O., Chantachaya, C. and Panyathanya, P. (1987). Toxicity of Chantaleela in animal model. Bull. Dept. Med. Sci. 29: 299 - 304.

9. Organization of Economic Co-operation and Development. (1981). The OECD guideline for testing of chemical: 408 Subchronic Oral Toxicity-Rodent: 90-day Study. France.

10. Organization of Economic Co-operation and Development. (2001). The OECD guideline for testing of chemical: 420 Acute Oral Toxicity. France.

11. Sacher, R.A. and McPherson, R.A. (2000). Test of liver function. In: Sacher, R.A., McPherson, R.A., Campos, J.M., Widmann, F.K. (eds) Widmann's clinical interpretation of laboratory test, $11^{\text {th }}$ ed. F.A. Davis Company, USA, pp $562-599$. 12. Williams, J.W., Nelson, D.A. and Morris, M.W. (1990). Examination of the blood. In: William, J.W. (ed) Hematology international, $4^{\text {th }}$ ed. Mc Graw-Hell, New York, pp $9-24$.

13. World Health Organization. (2000). General guidelines for methodologies on research and evaluation of traditional medicine. Switzerland. 